\title{
Methanogens: Methane Producers of the Rumen and Mitigation Strategies
}

\author{
Sarah E. Hook, ${ }^{1}$ André-Denis G. Wright, ${ }^{2}$ and Brian W. McBride ${ }^{1}$ \\ ${ }^{1}$ Department of Animal \& Poultry Science, University of Guelph, Guelph, ON, Canada N1G 2W1 \\ ${ }^{2}$ Department of Animal Science, University of Vermont, Burlington, VT 05405, USA \\ Correspondence should be addressed to Sarah E.Hook, shook@uoguelph.ca
}

Received 15 August 2010; Revised 3 November 2010; Accepted 7 December 2010

Academic Editor: Reinhard Hensel

Copyright (c) 2010 Sarah E. Hook et al. This is an open access article distributed under the Creative Commons Attribution License, which permits unrestricted use, distribution, and reproduction in any medium, provided the original work is properly cited.

\begin{abstract}
Methanogens are the only known microorganisms capable of methane production, making them of interest when investigating methane abatement strategies. A number of experiments have been conducted to study the methanogen population in the rumen of cattle and sheep, as well as the relationship that methanogens have with other microorganisms. The rumen methanogen species differ depending on diet and geographical location of the host, as does methanogenesis, which can be reduced by modifying dietary composition, or by supplementation of monensin, lipids, organic acids, or plant compounds within the diet. Other methane abatement strategies that have been investigated are defaunation and vaccines. These mitigation methods target the methanogen population of the rumen directly or indirectly, resulting in varying degrees of efficacy. This paper describes the methanogens identified in the rumens of cattle and sheep, as well as a number of methane mitigation strategies that have been effective in vivo.
\end{abstract}

\section{Introduction}

Methane production through enteric fermentation is of concern worldwide for its contribution to the accumulation of greenhouse gases in the atmosphere, as well as its waste of fed energy for the animal. Methane is produced in the rumen and hindgut of animals by a group of Archaea known collectively as methanogens, which belong to the phylum Euryarcheota. Among livestock, methane production is greatest in ruminants, as methanogens are able to produce methane freely through the normal process of feed digestion. Much research has been directed toward methane abatement strategies to be used in ruminants and has been reviewed elsewhere [1-7]. Abatement strategies are often limited by the diet fed, the management conditions, physiological state and use of the animal, as well as government regulations; resulting in difficulties applying a one size fits all approach to the problem of enteric methane mitigation. To this end, the aim of this paper is to provide background on enteric fermentation and methanogens, as well as some of the methane abatement strategies that have shown efficacy in vivo.

\section{Methane and Ruminants}

Greenhouse gases such as carbon dioxide, methane, nitrous oxide, and ozone contribute to climate change and global warming through their absorption of infrared radiation in the atmosphere [8]. Methane is classified as a trace gas and is estimated to have a total global concentration of $1774 \pm 1.8$ parts per billion (ppb), with a total increase of $11 \mathrm{ppb}$ since 1998 [9]. Methane is an especially potent trace gas due to its global warming potential, 25 times that of carbon dioxide, and its 12-year atmospheric lifetime; it is the second largest anthropogenic greenhouse gas, behind carbon dioxide $[9,10]$. Also, methane is able to increase ozone in the tropospheric region of the atmosphere where the greenhouse effect occurs, and increase stratospheric water vapour, both of which can add to the radiative force of the gas by approximately $70 \%$ [8]. Globally, $50-60 \%$ of methane emissions are from the agricultural sector, specifically from livestock production operations; the principal source of methane is from ruminant animals $[11,12]$.

Domesticated ruminants, such as cattle, sheep, and goats produce as much as 86 million metric tonnes $(\mathrm{Tg})$ of 
methane per year [13]. Approximately $18.9 \mathrm{Tg}$ are from dairy cattle, $55.9 \mathrm{Tg}$ are from beef cattle, and $9.5 \mathrm{Tg}$ are from sheep and goats [13]. Data from Johnson and Ward [14], estimates the global yearly methane contribution of buffalo to be $6.2-$ 8.1 Tg, 0.9-1.1 Tg from camels, and methane production within the hindgut of pigs and horses to be approximately $0.9-1.0 \mathrm{Tg}$ and $1.7 \mathrm{Tg}$, respectively.

Methane is produced in the rumen as a product of normal fermentation of feedstuffs. Although methane production can also occur in the lower gastrointestinal tract, as in nonruminants, $89 \%$ of methane emitted from ruminants is produced in the rumen and exhaled through the mouth and nose [15]. As methane is exhaled into the atmosphere, the ruminant suffers a loss of ingested feed-derived energy of approximately $2-12 \%$, depending upon the diet [14].

The loss of methane to the atmosphere varies based on the ruminant species. Estimates of diet-derived energy losses from methane for dairy cattle, range-cattle, and feedlot cattle vary from $5.5-9.0 \%, 6.0-7.5 \%$, and $3.5-6.5 \%$, respectively [14]. For buffalo and camels, a loss of diet energy in the form of methane ranges from $7.5-9.0 \%$ and $7.0-9.0 \%$, respectively [14]. Estimates of methane losses from ruminants also vary based on geographical location, feed quality, feed intake, feed composition, and the processing of the feed [14]. The impact of dietary components on methane emissions will be discussed further in Section 4.1

\section{Methanogens}

3.1. Characteristics and Ecosystem. Methanogens belong to the domain Archaea and the phylum Euryarchaeota [16]. Unlike Bacteria, methanogens lack peptidoglycan in the cell wall, replaced by pseudomurein in Methanobrevibacter and Methanobacterium, heteropolysaccharide in Methanosarcina, and protein in Methanomicrobium [16]. All methanogens have coenzyme $\mathrm{F}_{420}$, which is a cofactor necessary for enzymes such as hydrogenase and formate dehydrogenase, and received its name due to its absorbance at $420 \mathrm{~nm}$, which allows it to fluoresce blue-green at $470 \mathrm{~nm}$ [17]. Another coenzyme characteristic of methanogens is coenzyme $\mathrm{M}$, which is either produced by the methanogens, such as Methanobacterium, or is required from an external source, which is the case for Methanobrevibacter ruminantium [18]. Coenzyme M, or 2-mercaptoethanesulfonic acid, is methylated to produce methane [19].

The cell characteristics can vary greatly among methanogens as well. Methanobrevibacter ruminantium is rod shaped with variable motility and is able to use hydrogen and carbon dioxide, and formate as substrates for methane production [16]. Methanobacterium formicicum, which is in the same order (Methanobacteriales) as Methanobrevibacter, can be rod or filament shaped without motility, and is able to use the same substrates as Methanobrevibacter [16]. Methanomicrobium mobile is rod shaped and is motile, using both hydrogen and carbon dioxide, as well as formate to produce methane [16]. Finally, Methanosarcina barkeri and Methanosarcina mazeii are both coccoid shaped, but without motility [16]. The order Methanosarcinales contains the only methanogens with cytochromes, and can grow on the broadest range of substrates [20]. Cytochromes are membrane-bound electron carriers that play a role in the oxidation of methyl groups to carbon dioxide [21]. Methanosarcina barkeri is able to produce methane from hydrogen and carbon dioxide, acetate, methylamines, and methanol, whereas Methanosarcina mazeii can use the same substrates except hydrogen and carbon dioxide [16].

Methanogens with cytochromes have a growth yield of $7 \mathrm{~g}$ per mole of methane on hydrogen and carbon dioxide, and have a doubling time of greater than 10 hours [20]. Methanogens without cytochromes have a growth yield of $3 \mathrm{~g}$ per mole of methane on hydrogen and carbon dioxide, and have a doubling time minimum of 1 hour [20]. More in-depth discussion of taxonomy can be found in Garcia et al. [22] and a review of methanogens with emphasis on cytochromes can be found in Thauer et al. [20].

Methanogens are not only confined to the rumen in cattle and other ruminants. There has been recent interest in the presence of methanogens in the intestine of humans and Archaea have been found using 454 pyrosequencing in higher abundance in the large intestine of obese individuals [23]. Real-time PCR has been used to detect Methanobrevibacter smithii and Methanosphaera stadtmanae from human feces [24], and methanogens Methanobrevibacter gottschalkii, Methanobrevibacter thaueri, Methanobrevibacter woesei and Methanobrevibacter wolinii have been cultured from the feces of horse, cow, goose, and sheep, respectively [25]. Finally, Methanobrevibacter oralis was isolated in subgingival sites of patients with periodontal disease [26].

3.2. Methane Production. The principal methanogens in the bovine rumen utilize hydrogen and carbon dioxide, but there is a group of methanogens of the genus Methanosarcina that grow slowly on hydrogen and carbon dioxide and therefore maintain a distinct niche by utilizing methanol and methylamines to produce methane $[27,28]$. Formate, which is formed in the production of acetate, can also be used as a substrate for methanogenesis, although it is often converted quickly to hydrogen and carbon dioxide instead $[27,29]$. Volatile fatty acids (VFA) are not commonly used as substrates for methanogenesis as their conversion into carbon dioxide and hydrogen is a lengthy process, which is inhibited by rumen turnover [19]. Therefore, methanogenesis often uses the hydrogen and carbon dioxide produced by carbohydrate fermentation, as VFAs are formed [27]. By removing hydrogen from the ruminal environment as a terminal step of carbohydrate fermentation, methanogens allow the microorganisms involved in fermentation to function optimally and support the complete oxidation of substrates [30]. The fermentation of carbohydrates results in the production of hydrogen and if this end product is not removed, it can inhibit metabolism of rumen microorganisms [30].

3.3. Strains of Importance. The methanogen population present in the rumen may differ depending on the ruminant species being examined. Methanobrevibacter ruminantium and Methanomicrobium mobile were found to be 
the major methanogens in the ovine rumen by Yanagita and coworkers [31] using 16S rRNA-targeted fluorescent in situ hybridization. Wright and colleagues [32] identified clones from ovine rumen fluid similar to cultivated methanogens from the order Methanobacteriales. In another study of ovine rumen methanogens, Wright et al. [33] identified clones from ovine rumen fluid similar to methanogens of the orders Methanobacteriales and Methanomicrobiales, as well as previously unidentified sequences. Methanogens from the rumen of sheep and cattle were examined in a study by Nicholson et al. [34] using temporal gradient gel electrophoresis and found to be similar to those of the order Methanobacteriales and Methanosarcinales, although previously uncultured methanogens were also detected. Wright and colleagues [35] also completed a diversity analysis of sheep from Venezuela and concluded that the majority of clones identified belonged to the genus Methanobrevibacter, with the largest group of clones being similar to Methanobrevibacter gottschalkii.

In the bovine rumen, Whitford and coworkers [36] were able to detect Methanobrevibacter ruminantium as the largest group of methanogens in lactating dairy cattle fed total mixed ration, followed by Methanosphaera stadtmanae. Isolation of methanogens from grazing cattle by Jarvis et al. [37] suggested that Methanomicrobium mobile may be present at $10^{6}$ cells $/ \mathrm{ml}$. Methanobacterium formicicum was isolated as the second most common methanogen, followed by an isolate phenotypically similar to Methanosarcina barkeri [37]. Methanobrevibacter spp. was not identified in grazing cattle although it has been detected in cattle kept indoors and fed total mixed ration [36]. Wright and colleagues [38] identified methanogens from a clone library of the rumen fluid from feedlot cattle in Ontario, Canada fed a diet of predominantly corn. Clones were found to have greater than $95 \%$ sequence similarity with Methanobrevibacter ruminantium, Methanobrevibacter thaueri, Methanobrevibacter smithii, and Methanosphaera stadtmanae [38]. In the same study, a clone library was made from the rumen fluid of cattle from Prince Edward Island fed a diet of potato byproducts [38]. Clones were found to have greater than 95\% sequence similarity with Methanobrevibacter smithii, Methanobrevibacter ruminantium, and Methanobrevibacter thaueri [38]. Also, the rumen contents of cattle from Ontario and Prince Edward Island were found to have methanogen clones unique to the geographical location from which they originated, indicating that diet as well as geographical location of the host may play a role in the methanogen population diversity present.

Methanogen strain presence has also been investigated as it relates to feed efficiency. Recent work by Zhou and colleagues $[39,40]$ investigated the diversity of methanogens in the rumen of beef cattle with either high or low feed efficiencies. In the 2009 study, Methanosphaera stadtmanae and Methanobrevibacter sp. AbM4 were in greater numbers among the inefficient animals, while the total size of the rumen methanogen population was not significantly different between animals with different feed efficiencies [39]. In the 2010 study, where they also had cattle fed either a high- or low- energy diet, the high-energy diet was associated with the presence of Methanobrevibacter smithii SM9 and Methanobrevibacter sp. AbM4, while the predominant methanogen in the low-energy diet was Methanobrevibacter ruminantium [40]. Methanobrevibacter smithii was only found in high efficiency animals.

Furthermore, the location within the rumen from which the methanogens are detected plays a role in the methanogens identified. In a study by Shin and colleagues [41], a Korean cow was fed rice hull and concentrate, and samples from the rumen fluid, rumen solid, and rumen epithelium were removed. The predominant rumen methanogen in the rumen fluid and rumen epithelium was found to belong to the family Methanomicrobiaceae [41]. The rumen solid was predominantly made up of methanogens of the family Methanobacteriaceae, which is the methanogen family commonly detected within the bovine rumen [41].

3.4. Relationship with Other Microorganisms. Methanogens are known to have symbiotic relationships involving interspecies hydrogen transfer with rumen microorganisms, especially with rumen protozoa where the methanogens can be associated intracellularly and extracellularly [30]. Common protozoa in the bovine rumen found to have such a relationship are from the genera Entodinium, Polyplastron, Epidinium, and Ophryoscolex, while the methanogens most often associated with protozoa are from the orders Methanobacteriales and Methanomicrobiales [30]. Anaerobic fungi, such as Neocallimastix frontalis, have also been found to have a relationship with methanogens involving interspecies hydrogen transfer whereby the fungi's enzymatic activity has increased and metabolism has shifted towards acetate production [42-44].

\section{Methane Reduction Strategies}

The topic of the relationship that methanogens have with other microorganisms in the rumen is especially important when considering methane mitigation strategies. Methane mitigation is effective in one of two ways: either a direct effect on the methanogens, or an indirect effect caused by the impact of the strategy on substrate availability for methanogenesis, usually through an effect on the other microbes of the rumen. Both approaches will be discussed here with focus on strategies that have shown efficacy in vivo (see Table 1).

4.1. Dietary Composition. The components of the diet fed, especially type of carbohydrate, are important for methane production as they are able to influence the ruminal $\mathrm{pH}$ and subsequently alter the microbiota present [45]. Ellis et al. [11] were able to predict methane production in dairy and beef cattle based on dry matter intake, neutral detergent fibre, and lignin content of the diet, measurements easily acquired from farms, with an $R^{2}$ of 0.71 . The digestibility of cellulose and hemicellulose are strongly related to methane production, more so then soluble carbohydrate [46]. In a study by Holter and Young [46], a positive relationship was found 
TABLE 1: Methane abatement strategies, mechanism of abatement, and considerations for use.

\begin{tabular}{|c|c|c|}
\hline Methane abatement strategy & Mechanism of abatement activity & $\begin{array}{l}\text { Considerations when selecting abatement } \\
\text { strategy }\end{array}$ \\
\hline \multicolumn{3}{|l|}{ Dietary composition } \\
\hline $\begin{array}{l}\text { Increase hemicellulose/starch } \\
\text { Decrease cell wall components } \\
\text { Grinding }\end{array}$ & $\begin{array}{l}\text { Increased passage rate; greater proportion } \\
\text { propionate versus acetate; reduced ruminal } \mathrm{pH}\end{array}$ & $\begin{array}{l}\text { Shift methanogensis to hind gut or manure, risk } \\
\text { of subacute ruminal acidosis (SARA) }\end{array}$ \\
\hline \multicolumn{3}{|l|}{ Lipids } \\
\hline $\begin{array}{l}\text { Fatty acids } \\
\text { Oils } \\
\text { Seeds } \\
\text { Tallow }\end{array}$ & $\begin{array}{l}\text { Inhibition of methanogens and protozoa; greater } \\
\text { proportion propionate versus acetate; } \\
\text { biohydrogenation }\end{array}$ & $\begin{array}{l}\text { Effect on palatability, intake, performance, and } \\
\text { milk components; varies with diet and ruminant } \\
\text { species; long-term studies needed }\end{array}$ \\
\hline \multicolumn{3}{|l|}{ Defaunation } \\
\hline $\begin{array}{l}\text { Chemical } \\
\text { Feed additives }\end{array}$ & $\begin{array}{l}\text { Removes associated methanogens; less hydrogen } \\
\text { for methanogenesis }\end{array}$ & $\begin{array}{l}\text { Adaptation of microbiota may occur; varies with } \\
\text { diet; maintenance of defaunated animals }\end{array}$ \\
\hline Methanogen Vaccine & Host immune response to methanogens & $\begin{array}{l}\text { Vaccine targets; diet and host geographical } \\
\text { location differences }\end{array}$ \\
\hline Monensin & $\begin{array}{l}\text { Inhibits protozoa and gram-positive bacteria; } \\
\text { lack of substrate for methanogenesis }\end{array}$ & $\begin{array}{l}\text { Adaptation of microbiota may occur; varies with } \\
\text { diet and animal; banned in the EU }\end{array}$ \\
\hline \multicolumn{3}{|l|}{ Plant Compounds } \\
\hline $\begin{array}{l}\text { Condensed tannins } \\
\text { Saponins } \\
\text { Essential oils }\end{array}$ & $\begin{array}{l}\text { Antimicrobial activity; reduced hydrogen } \\
\text { availability }\end{array}$ & $\begin{array}{l}\text { Optimum dosage unknown; more in vivo } \\
\text { research needed; long-term studies needed; may } \\
\text { affect digestibility; residues unknown }\end{array}$ \\
\hline \multicolumn{3}{|l|}{ Organic Acids } \\
\hline $\begin{array}{l}\text { Fumarate } \\
\text { Malate }\end{array}$ & $\begin{array}{l}\text { Hydrogen sink, greater proportion propionate } \\
\text { versus acetate }\end{array}$ & $\begin{array}{l}\text { Varies with diet; more in vivo research needed; } \\
\text { long-term studies needed; may affect } \\
\text { digestibility }\end{array}$ \\
\hline
\end{tabular}

between digestibility of hemicellulose and methane output in forage fed nonlactating cows. A negative relationship was found between digestibility of cellulose and methane output [46]. Sauvant and Giger-Reverdin [47] found the relationship between methane production and proportion of concentrate in the diet to be curvilinear, with methane losses of $6-7 \%$ of gross energy (GE) being constant at 30$40 \%$ concentrate levels in the diet and then decreasing to $2-$ $3 \%$ of GE with a concentrate proportion of $80-90 \%$. The starch component of the diet is also known to promote propionate formation, through a shift to amylolytic bacteria, and a reduction in ruminal $\mathrm{pH}$, leading to a decrease in methanogenesis [48]. Johnson and Johnson [45] stated that the digestion of cell wall fiber increases methane production, by increasing the amount of acetate produced in relation to propionate. The increase in methane output is due to the fermentation of acetate, which provides a methyl group for methanogenesis [49]. Grinding forage feed before it is ingested by the cows also seems to decrease the production of methane, presumably by increasing the rate of digestion and flow through the gastrointestinal tract, thus limiting the time available for methane to be produced within the rumen [45].

It is important to note that increasing the amount of rapidly fermentable carbohydrates in a diet can increase the rate of passage from the rumen, as well as lower the ruminal $\mathrm{pH}$ (see Table 1). Increased passage rates can shift methanogenesis to the hind gut, as well as to the manure, possibly off setting any reductions in ruminal methane outputs [50]. Further, the ruminal digestion of rapidly fermentable carbohydrates can increase the production of VFAs. If VFA production is greater than absorption, the $\mathrm{pH}$ in the rumen will drop, leading to subacute ruminal acidosis (SARA) and disruption of the rumen microbiota [51].

4.2. Lipids. Lipids, such as fatty acids and oils, are options for feed supplementation that have been investigated both in vitro and in vivo for their effects on methanogenesis. Increased lipid content in the feed is thought to decrease methanogenesis through inhibition of protozoa, increased production of propionic acid, and by "biohydrogenation of unsaturated fatty acids" [45]. Unsaturated fatty acids 
may be used as hydrogen acceptors as an alternative to the reduction of carbon dioxide [45]. Also, fatty acids are thought to inhibit methanogens directly through binding to the cell membrane and interrupting membrane transport [52]. Interestingly, Kong et al. [53] detected Archaea using fluorescence in situ hybridization (FISH) in the rumen of dairy cows supplemented with flaxseed, and did not find any obvious differences in the proportion of Archaea present with flaxseed addition. The authors stated that it was possible fatty acid supplementation was affecting activity instead of quantity of methanogens.

A meta-analysis of methane output with lipid supplementation in lactating dairy cows found a $2.2 \%$ decrease in methane per $1 \%$ of supplemented lipid in the diet [54]. In cattle and sheep, Beauchemin et al. [55] found an association of $5.6 \%$ methane reduction per percentage unit of lipid added to the diet. There are many factors that may account for varying effects of lipids on methane abatement, such as the ruminant species, experimental diet, and the type of lipid used. An excellent review of in vivo experiments using lipid supplementation to investigate methane abatement can be found in Martin et al. [6].

4.2.1. Fatty Acids. A number of fatty acids have been investigated in vivo for methane suppressing effect. Myristic acid was found to reduce methane by $22 \%$ in sheep fed a forage-based diet and $58 \%$ in a concentrate-based diet when $50 \mathrm{mg} / \mathrm{kg}$ DM was used [56]. Odongo et al. [57] measured a $36 \%$ methane reduction in dairy cattle fed a total mixed ration with $5 \%$ myristic acid supplementation on a dry matter (DM) basis. In vitro studies have found fatty acids used in combination have the greatest suppression of methanogenesis due to a synergistic effect $[52,58]$. Therefore, it is likely that oil supplementation would provide a more dramatic depression of methane production than individual fatty acids [58].

4.2.2. Oils. Oils extracted from plant sources usually contain a favourable amount of medium- to long-chain fatty acids $[58,59]$. Refined soy oil fed to beef bulls at $6 \%$ inclusion reduced methane production by $39 \%$ in terms of litres per day $(1 / d)[60]$. Sunflower oil is more often studied and has resulted in an 11.5-22.0\% reduction in methanogenesis $[59,61]$. Sunflower oil has also been combined with linseed oil at a ratio of $1: 3$ and fed to sheep on a pasturebased diet in a dose-response trial, but at $1.2-5 \%$ oil inclusion on a dry matter basis, there was no significant reduction in methanogenesis [62]. Linseed oil supplemented at a level of $5 \%$ of DM to lactating dairy cows resulted in a $55.8 \%$ reduction in grams of methane per day [63]. Coconut oil is the most popular oil for methane abatement experiments and has been found to induce significant reductions in methanogenesis, although the extent of the reduction varies from $13-73 \%$, depending on the inclusion level, diet, and ruminant species used $[60,64,65]$. Since coconut oil has a ratio of lauric to myristic acid of $2.6: 1.0$, similar to the effective ratios for methane abatement of $4: 1,3: 2$, and $2.5: 2.5$ found in vitro by Soliva et al. [58], it is expected that this oil would provide significant reductions in methanogenesis in vivo. Palm kernel oil has a ratio of lauric to myristic acid of $3: 1$, suggesting a greater efficacy for methane abatement compared to coconut oil, but to our knowledge, there are currently no published reports of palm kernel oil supplementation in vivo. In an in vitro study by Dohme et al. [66], coconut oil reduced methane by $21 \%$ while palm kernel oil reduced methane by $34 \%$, providing more evidence that palm kernel oil may be more efficacious. However, it is important to note, that in vivo studies involving oil supplementation are often accompanied by a reduction in dry matter intake, which can also result in reduced methane production [65].

4.2.3. Other Lipid Sources. Other lipid sources, such as tallow and seeds, have also been investigated for methane suppressing effects. Beauchemin et al. [61] supplemented heifers with $34 \mathrm{~g}$ of tallow per $\mathrm{kg} \mathrm{DM}$ and found an $11 \%$ reduction in $\mathrm{g}$ of methane per kg DMI. Jordan et al. [67] supplemented beef bulls with whole soybean at an inclusion level of $27 \%$ $\mathrm{DM}$ and, despite palatability issues resulting in up to $60 \%$ refusal, found a $25 \%$ reduction of liters methane per day. Beauchemin et al. $[61,68]$ conducted two experiments using sunflower seed supplementation with heifers and dairy cows and found a $23 \%$ and $10.4 \%$ reduction in methanogenesis, respectively. Beauchemin et al. [68] also supplemented dairy cows with flaxseed and canola seed at 3.3\% (DM basis) and reductions in methane were found to be $17.8 \%$ and $16.0 \%$, respectively, as $\mathrm{g} / \mathrm{kg}$ DMI [68]. Machmüller et al. [65] found reductions in methane on a $\mathrm{kg}$ live weight basis from supplementation of rapeseed, sunflower seed, and linseed of $19 \%, 27 \%$, and $10 \%$, respectively, in growing lambs. Finally, Grainger et al. [69] fed $2.61 \mathrm{~kg}$ (DM basis) of whole cottonseeds to lactating cows and found the average reduction in methane over the twelve-week experiment was $2.9 \%$ per $1 \%$ fat addition, with $1.5 \%$ reduction at week three and $4.4 \%$ at week twelve.

No matter what the lipid form used for supplementation, it is important to consider the ruminant species and the diet being examined, as methane reductions can vary depending on the feed components present (see Table 1) [6]. Further, lipid inclusion can affect palatability, intake, animal performance, and milk components, all of which can have implications for practical on-farm use [57, 67]. Finally, the majority of in vivo experiments conducted to investigate lipids as methane abatement strategies are shortterm, making it nearly impossible to draw conclusions about long-term repressive effects. Therefore, long-term supplementation experiments need to be conducted to thoroughly gauge the efficacy of lipid supplementation as an abatement strategy.

4.3. Defaunation Treatment. Defaunation, which is the removal of protozoa from the rumen, has been used to investigate the role of protozoa in rumen function, and also to study the effect on methane production. Rumen protozoa, as stated previously, share a symbiotic relationship with methanogens, participating in interspecies hydrogen 
transfer, which provides methanogens with the hydrogen they require to reduce carbon dioxide to methane [70]. It has been estimated that the methanogens associated with the ciliate protozoa, both intracellularly and extracellularly, are responsible for 9 to $37 \%$ of the methane production in the rumen [70-72]. For this reason, treatments that decrease the protozoal population of the rumen, may also decrease the protozoa-associated methanogen population and therefore, decrease the methane production within the rumen. Treatments that have been used include copper sulphate, acids, surface-active chemicals, triazine, lipids, tannins, ionophores, and saponins [19]. It has been suggested that the effect of defaunation on methane output is diet dependent. Hegarty [73] found that defaunation reduced methane output $13 \%$, but the magnitude of reduction varied with diet. The greatest reduction in methane production with defaunation was measured on a high-concentrate diet, likely because protozoa are the predominant source of hydrogen for methanogenesis on starch-based diets. Although, Hegarty et al. [74] also found that there was no main effect of protozoa on rumen methane production, when investigated in chemically-defaunated, defaunated from birth, and faunated lambs. Another consideration is whether there are long-term effects of defaunation on methanogenesis (see Table 1). Morgavi et al. [75] found methane reductions due to defaunation to last more than two years, but a study of ionophore supplementation by Guan et al. [76] found that reductions in rumen methanogenesis were short-lived and hypothesized this was due to adaptation of ciliate protozoa. Finally, maintenance of defaunated animals can be difficult. A recent study found that transfer of viable protozoa to defaunated animals does not occur readily through contact with feed or feces of faunated animals, nor with direct contact with faunated animals, but does occur through contaminated water [77].

4.4. Vaccine. Another methane reduction strategy that is being investigated is the development of a vaccine that would stimulate the ruminant's immune system to produce antibodies against methane-producing methanogens [78]. In a study by Wright and colleagues [78], two vaccines were developed, named VF3 (based on three methanogen strains) and VF7 (based on seven methanogen strains), which produced a $7.7 \%$ methane reduction per dry matter intake, despite only approximately $20 \%$ of the methanogen population being targeted. The same research group also created a vaccine based on five methanogen strains that was administered in three vaccinations to sheep [79]. Although the vaccine targeted $52 \%$ of the methanogens present in the rumen of the sheep, methane output went up 18\% with vaccination, leading the authors to believe that the vaccine was not targeting the methanogens capable of producing most of the methane. Another consideration when using vaccines against methanogens is that the rumen methanogen population present can differ based on diet and geographical location of the host, making a single-targeted approach difficult [38].

An additional vaccine has recently been developed using subcellular fractions of Methanobrevibacter ruminantium M1
[80]. Twenty sheep were vaccinated and then revaccinated three weeks later and the antisera was found to cause agglutination of methanogens and decrease growth and methane production in vitro. In vivo testing of the efficacy of the vaccine on methanogens was not conducted (see Table 1).

4.5. Monensin. Monensin, an antibiotic produced by Streptomyces cinnamonensis, is marketed in North America to increase feed efficiency and weight gain, increase milk production, and decrease milk fat [81]. More recently, interest has been renewed in monensin as a mitigation strategy for methane production, as it is known to inhibit gram-positive microorganisms responsible for supplying methanogens with substrate for methanogenesis. The effects caused by monensin on the microbial cell are mediated by its ability to interfere with ion flux $[82,83]$. Monensin selects for gram-negative microorganisms, which causes a shift towards propionate production in the rumen $[82,83]$. For this reason, it is hypothesized that monensin does not affect methane production by inhibiting methanogens, but instead inhibits the growth of the bacteria, and protozoa, providing a substrate for methanogenesis [82-85]. This statement is strengthened by the fact that when rumen fluid was dosed with monensin in vitro, methane production decreased until a supply of hydrogen was given, at which time methane production resumed [83].

The reductions in methanogenesis following ionophore supplementation vary from minor to $25 \%$, with differing outcomes for the duration of these effects [45]. In a study designed to measure methane output in lactating dairy cows receiving monensin supplementation, cows were fed monensin-supplemented feed for 3 weeks after a transitional period, fed a monensin-free diet for 5 months, and then fed monensin-supplemented feed for another 3 weeks [81]. It was found that although during the first treatment with monensin the cows had decreased feed intake, increased propionate production, and decreased methane outputs, the second treatment of monensin did not cause the previously seen effects. There was confounding within this study of treatment and animal, but the authors stated that adaptation of the rumen microflora to monensin may have occurred during the first treatment, inhibiting the effect of the drug during the second treatment.

Guan et al. [76] investigated the use of monensin in steers and the effect of supplementation on methane output. Steers were fed either a low-concentrate diet or a highconcentrate diet while supplemented with monensin. For the low-concentrate diet, an initial reduction in methane output, as measured with sulfur hexafluoride $\left(\mathrm{SF}_{6}\right)$ tracer gas, was found of $27 \%$ over the initial four weeks, in combination with a reduction in the ciliate protozoal population of $77 \%$ [76]. For the high-concentrate diet, within the first two weeks there was a $30 \%$ reduction in methane output along with an $83 \%$ reduction in the ciliate protozoal population [76]. The methane levels returned to baseline and the protozoal numbers returned to baseline as well after six and four weeks, respectively. The authors concluded that the affect of monensin on methane levels in the rumen is related to the ciliate protozoal population and as this population adapted 
to monensin, the methane levels in the rumen returned to pretreatment levels.

More recently, long-term monensin supplementation was investigated in lactating dairy cows fed a milking cow total mixed ration [86]. Twenty-four cows were pair-fed and baseline measurements of methane output were measured. Monensin supplementation was included in the diet of half of the paired animals while the other half was fed the same diet without monensin, and methane output was measured for each pair monthly for six months. Monensin treatment was found to cause a 7-9\% reduction in methane output versus control cows and this reduction was sustained for the entire treatment period with no adaptation detected [86]. In conjunction with this experiment, rumen samples were obtained for molecular analysis of changes in the methanogen population with monensin supplementation [87]. No significant differences in the number or diversity of methanogens were found, confirming that monensin is able to suppress methanogenesis through an indirect effect on methanogens.

Therefore, although monensin supplementation has been shown to effectively reduce methane output in ruminants, there are a few factors that may impact the efficacy (see Table 1). First, there appears to be differences in the degree of abatement depending on the diet and animal used $[76,86]$. Also, the ciliate population present in the rumen may affect the outcome of supplementation, with adaptation being a possibility [76]. Finally, monensin has been banned in the European Union, so an alternate methane abatement method would be required in those countries.

4.6. Plant Compounds. The three main plant compounds effective at reducing methane emissions in vitro are condensed tannins, saponins, and essential oils. In vivo, the efficacy of these compounds varies in terms of methane abatement.

Condensed tannins are thought to directly inhibit methanogens, as well as indirectly limit methanogenesis through a reduction in hydrogen availability [88]. Condensed tannincontaining Lespedeza cuneata was fed to goats ad libitum and found to reduce methane $57 \%$ in terms of $\mathrm{g} / \mathrm{kg} \mathrm{DMI}$, compared to goats fed a mixture of Digitaria ischaemum and Festuca arundinacea [89]. Sheep consuming $41 \mathrm{~g}$ of tannincontaining Acacia mearnsii per $\mathrm{kg}$ DM were found to have a $13 \%$ reduction in methanogensisis [90]. Tannin-containing Callinada calothyrsus and Fleminga macrophylla also reduced methane $24 \%$ in lambs [91], but an extract of condensed tannin from Schinopsis quebrachocolorado [92] and tannincontaining sorghum silage [93] fed to cattle did not suppress methanogenesis.

Saponins have been shown in vitro to inhibit protozoa, as well as limit hydrogen availability for methanogensis [94]. A recent study by Holtshausen et al. [95] supplemented cows with whole-plant Yucca schidigera powder at $10 \mathrm{~g} / \mathrm{kg}$ DM or whole-plant Quillaja saponaria powder at $10 \mathrm{~g} / \mathrm{kg} \mathrm{DM}$, both of which contain saponin. The authors stated that previous studies in vitro had found reductions in methane at higher inclusion levels ( $15 \mathrm{~g} / \mathrm{kg} \mathrm{DM}$ and greater), but these high levels were avoided in vivo in order to minimize effects on digestibility [94]. No effect of the plant supplementation was found in vivo and the authors concluded that the in vitro reductions in methane were likely due to reduced feed digestion and fermentation [95]. This makes in vivo supplementation difficult because higher feeding levels may be required to measure reductions in methane output, but these reductions would be at a cost to feed-digestibility.

Essential oils have antimicrobial activities that act in a similar way to monensin by inhibiting gram-positive bacteria $[96,97]$. In this way, essential oils can reduce the amount of available hydrogen for methanogensis. Few in vivo studies have been conducted, but one study by Beauchemin and McGinn [98] where heifers were fed $1 \mathrm{~g} / \mathrm{d}$ of essential oil and spice extract found no effect on methane output and a negative effect on feed digestibility.

Clearly, more research in necessary in vivo with essential oils, as well as condensed tannins and saponins, to determine the optimal dosage where methanogenesis is reduced without side effects on digestibility (see Table 1). Also, long-term studies are required to determine whether the microbes are able to adapt to supplementation and resume methanogenesis at baseline levels. Finally, it is important to study whether any residues of supplementation appear in milk or meat to make this a viable option for methane abatement in production animals [97].

4.7. Organic Acids. In vivo effects of organic acid supplementation on methane abatement are variable. Wood and colleagues [99] supplemented $100 \mathrm{~g} / \mathrm{kg}$ fumaric acid in the free or encapsulated form to growing lambs and found a $62 \%$ and $76 \%$ reduction in methane output, respectively. Fumaric acid was also fed to growing beef cattle at $175 \mathrm{~g} / \mathrm{d}$, steers at $80 \mathrm{~g} / \mathrm{d}$, and wethers at $4-10 \mathrm{~g} / 100 \mathrm{~g}$ (DM basis), but was not found to significantly reduce methane emissions, although suppression of DMI was found at higher inclusion levels [59, 100]. Beef heifers were supplemented with $3.75 \%$ and $7.5 \%$ malic acid on a DM basis and methane output reductions of $3 \%$ and $9 \%$ as $\mathrm{g} / \mathrm{kg}$ DMI were measured, respectively [101]. The authors stated that the effect of organic acid supplementation on methane abatement appears to be influenced by diet, with greater abatement when high-concentrate diets are fed. This is due to a greater effect on the acetate-topropionate ratio in the rumen, in addition to its ability to act as a hydrogen sink [101]. Based on the in vivo studies presented here, it appears that organic acids may provide beneficial effects in terms of methane abatement, but further in vivo experiments need to be conducted to determine the optimal conditions for use (see Table 1). Additionally, long-term supplementation studies need to be conducted to confirm that any benefits observed are lasting.

\section{Summary}

For more than two decades, researchers have been working to identify, quantify, and inhibit methanogens and methanogenesis through various methane mitigation strategies. Although a great deal of information has been gleaned from these experiments, including identification of a number of methanogen strains in the rumens of cattle and sheep around 
the world, as well as mitigation strategies with varying degrees of feasibility and efficacy, there is still more research to be done in this field. Also, many methane mitigation strategies work through an indirect effect on methanogens, by limiting substrate availability for methanogenesis. By targeting the methanogens directly, there may be a greater reduction in methanogenesis, as well as a more sustainable reduction, making strategies such as the use of vaccines and dietary fatty acids, which inhibit methanogens and protozoa, especially promising.

\section{Acknowledgment}

The authors wish to acknowledge funding provided by the Natural Science and Engineering Research Council of Canada (BWM \& SEH).

\section{References}

[1] E. Kebreab, K. Clark, C. Wagner-Riddle, and J. France, "Methane and nitrous oxide emissions from Canadian animal agriculture: a review," Canadian Journal of Animal Science, vol. 86, no. 2, pp. 135-158, 2006.

[2] K. A. Beauchemin, T. A. McAllister, and S. M. McGinn, "Dietary mitigation of enteric methane from cattle," $C A B$ Reviews: Perspectives in Agriculture, Veterinary Science, Nutrition and Natural Resources, vol. 4, no. 9, pp. 1-18, 2009.

[3] S. Kumar, A. K. Puniya, M. Puniya et al., "Factors affecting rumen methanogens and methane mitigation strategies," World Journal of Microbiology and Biotechnology, vol. 25, no. 9, pp. 1557-1566, 2009.

[4] B. M. Buddle, M. Denis, G. T. Attwood et al., "Strategies to reduce methane emissions from farmed ruminants grazing on pasture," The Veterinary Journal. In press.

[5] R. J. Eckard, C. Grainger, and C. A. M. de Klein, "Options for the abatement of methane and nitrous oxide from ruminant production: a review," Livestock Science, vol. 130, no. 1-3, pp. 47-56, 2010.

[6] C. Martin, D. P. Morgavi, and M. Doreau, "Methane mitigation in ruminants: from microbe to the farm scale," Animal, vol. 4, no. 3, pp. 351-365, 2010.

[7] M. Shibata and F. Terada, "Factors affecting methane production and mitigation in ruminants," Animal Science Journal, vol. 81, no. 1, pp. 2-10, 2010.

[8] D. A. Lashof and D. R. Ahuja, "Relative contributions of greenhouse gas emissions to global warming," Nature, vol. 344, no. 6266, pp. 529-531, 1990.

[9] P. Forster, V. Ramaswamy, P. Artaxo et al., "Changes in atmospheric constituents and in radiative forcing," in Climate Change 2007: The Physical Science Basis. Contribution of Working Group I to the Fourth Assessment Report of the Intergovernmental Panel on Climate Change, S. Solomon, D. Qin, M. Manning et al., Eds., Cambridge University Press, Cambridge, UK, 2007.

[10] IPCC, "Intergovernmental panel on climate change," in Climate Change 2001: A Scientific Basis, J. T. Houghton, Y. Ding, and D. J. Griggs, Eds., Cambridge University Press, Cambridge, UK, 2001.

[11] J. L. Ellis, E. Kebreab, N. E. Odongo, B. W. McBride, E. K. Okine, and J. France, "Prediction of methane production from dairy and beef cattle," Journal of Dairy Science, vol. 90, no. 7, pp. 3456-3467, 2007.
[12] National Research Council, The Scientific Basis for Estimating Air Emissions from Animal Feeding Operations, National Academy Press, Washington, DC, USA, 2002.

[13] A. J. McMichael, J. W. Powles, C. D. Butler, and R. Uauy, "Food, livestock production, energy, climate change, and health," The Lancet, vol. 370, no. 9594, pp. 1253-1263, 2007.

[14] D. E. Johnson and G. M. Ward, "Estimates of animal methane emissions," Environmental Monitoring and Assessment, vol. 42, no. 1-2, pp. 133-141, 1996.

[15] R. M. Murray, A. M. Bryant, and R. A. Leng, "Rates of production of methane in the rumen and large intestine of sheep," British Journal of Nutrition, vol. 36, no. 1, pp. 1-14, 1976.

[16] W. E. Balch, G. E. Fox, and L. J. Magrum, "Methanogens: reevaluation of a unique biological group," Microbiological Reviews, vol. 43, no. 2, pp. 260-296, 1979.

[17] K. D. Ashby, T. A. Casey, M. A. Rasmussen, and J. W. Petrich, "Steady-state and time-resolved spectroscopy of F420 extracted from methanogen cells and its utility as a marker for fecal contamination," Journal of Agricultural and Food Chemistry, vol. 49, no. 3, pp. 1123-1127, 2001.

[18] P. E. Rouviere and R. S. Wolfe, "Novel biochemistry of methanogenesis," Journal of Biological Chemistry, vol. 263, no. 17, pp. 7913-7916, 1988.

[19] P. N. Hobson and C. S. Stewart, The Rumen Microbial Ecosystem, Chapman and Hall, London, UK, 1997.

[20] R. K. Thauer, A. K. Kaster, H. Seedorf, W. Buckel, and R. Hedderich, "Methanogenic archaea: ecologically relevant differences in energy conservation," Nature Reviews Microbiology, vol. 6, no. 8, pp. 579-591, 2008.

[21] W. Kühn, K. Fiebig, and H. Hippe, "Distribution of cytochromes in methanogenic bacteria," FEMS Microbiology Letters, vol. 20, no. 3, pp. 407-410, 1983.

[22] J. L. Garcia, B. K. C. Patel, and B. Ollivier, "Taxonomic, phylogenetic, and ecological diversity of methanogenic Archaea," Anaerobe, vol. 6, no. 4, pp. 205-226, 2000.

[23] H. Zhang, J. K. DiBaise, A. Zuccolo et al., "Human gut microbiota in obesity and after gastric bypass," Proceedings of the National Academy of Sciences of the United States of America, vol. 106, no. 7, pp. 2365-2370, 2009.

[24] B. Dridi, M. Henry, A. El Khéchine, D. Raoult, and M. Drancourt, "High prevalence of Methanobrevibacter smithii and Methanosphaera stadtmanae detected in the human gut using an improved DNA detection protocol," PLoS One, vol. 4, no. 9, Article ID e7063, 2009.

[25] T. L. Miller and C. Lin, "Description of Methanobrevibacter gottschalkii sp. nov., Methanobrevibacter thaueri sp. nov., Methanobrevibacter woesei sp. nov. and Methanobrevibacter wolinii sp. nov," International Journal of Systematic and Evolutionary Microbiology, vol. 52, no. 3, pp. 819-822, 2002.

[26] A. Ferra, T. Brusa, A. Rutili, E. Canzi, and B. Biavati, "Isolation and characterization of Methanobrevibacter oralis sp. nov," Current Microbiology, vol. 29, no. 1, pp. 7-12, 1994.

[27] R. E. Hungate, W. Smith, T. Bauchop, I. Yu, and J. C. Rabinowitz, "Formate as an intermediate in the bovine rumen fermentation," Journal of Bacteriology, vol. 102, no. 2, pp. 389-397, 1970.

[28] J. A. Patterson and R. B. Hespell, "Trimethylamine and methylamine as growth substrates for rumen bacteria and Methanosarcina barkeri," Current Microbiology, vol. 3, no. 2, pp. 79-83, 1979.

[29] D. B. Archer and J. E. Harris, "Methanogenic bacteria and methane production in various habitats," in Anaerobic Bacteria in Habitats Other than Man, E. M. Barnes and G. C. 
Mead, Eds., pp. 185-223, Blackwell Scientific, Oxford, UK, 1986.

[30] R. Sharp, C. J. Ziemer, M. D. Stern, and D. A. Stahl, “Taxonspecific associations between protozoal and methanogen populations in the rumen and a model rumen system," FEMS Microbiology Ecology, vol. 26, no. 1, pp. 71-78, 1998.

[31] K. Yanagita, Y. Kamagata, M. Kawaharasaki, T. Suzuki, Y. Nakamura, and H. Minato, "Phylogenetic analysis of methanogens in sheep rumen ecosystem and detection of Methanomicrobium mobile by fluorescence in situ hybridization," Bioscience, Biotechnology and Biochemistry, vol. 64, no. 8, pp. 1737-1742, 2000.

[32] A. D. G. Wright, A. J. Williams, B. Winder, C. T. Christophersen, S. L. Rodgers, and K. D. Smith, "Molecular diversity of rumen methanogens from sheep in Western Australia," Applied and Environmental Microbiology, vol. 70, no. 3, pp. 1263-1270, 2004.

[33] A. D. Wright, A. F. Toovey, and C. L. Pimm, "Molecular identification of methanogenic archaea from sheep in Queensland, Australia reveal more uncultured novel archaea," Anaerobe, vol. 12, no. 3, pp. 134-139, 2006.

[34] M. J. Nicholson, P. N. Evans, and K. N. Joblin, "Analysis of methanogen diversity in the rumen using temporal temperature gradient gel electrophoresis: identification of uncultured methanogens," Microbial Ecology, vol. 54, no. 1, pp. 141-150, 2007.

[35] A. D. G. Wright, X. Ma, and N. E. Obispo, "Methanobrevibacter phylotypes are the dominant methanogens in sheep from Venezuela," Microbial Ecology, vol. 56, no. 2, pp. 390394, 2008.

[36] M. F. Whitford, R. M. Teather, and R. J. Forster, "Phylogenetic analysis of methanogens from the bovine rumen," $B M C$ Microbiology, vol. 1, pp. 1-5, 2001.

[37] G. N. Jarvis, C. Strömpl, D. M. Burgess, L. C. Skillman, E. R. B. Moore, and K. N. Joblin, "Isolation and identification of ruminal methanogens from grazing cattle," Current Microbiology, vol. 40, no. 5, pp. 327-332, 2000.

[38] A. D. G. Wright, C. H. Auckland, and D. H. Lynn, "Molecular diversity of methanogens in feedlot cattle from Ontario and Prince Edward Island, Canada," Applied and Environmental Microbiology, vol. 73, no. 13, pp. 4206-4210, 2007.

[39] MI. Zhou, E. Hernandez-Sanabria, and L. G. Le, "Assessment of the microbial ecology of ruminal methanogens in cattle with different feed efficiencies," Applied and Environmental Microbiology, vol. 75, no. 20, pp. 6524-6533, 2009.

[40] M. Zhou, E. Hernandez-Sanabria, and L. L. Guan, "Characterization of variation in rumen methanogenic communities under different dietary and host feed efficiency conditions, as determined by PCR-denaturing gradient gel electrophoresis analysis," Applied and Environmental Microbiology, vol. 76, no. 12, pp. 3776-3786, 2010.

[41] E. C. Shin, B. R. Choi, W. J. Lim et al., "Phylogenetic analysis of archaea in three fractions of cow rumen based on the $16 \mathrm{~S}$ rDNA sequence," Anaerobe, vol. 10, no. 6, pp. 313-319, 2004.

[42] T. Bauchop and D. O. Mountfort, "Cellulose fermentation by a rumen anaerobic fungus in both the absence and the presence of rumen methanogens," Applied and Environmental Microbiology, vol. 42, no. 6, pp. 1103-1110, 1981.

[43] D. O. Mountfort, R. A. Asher, and T. Bauchop, "Fermentation of cellulose to methane and carbon dioxide by a rumen anaerobic fungus in a triculture with Methanobrevibacter sp. strain RA1 and Methanosarcina barkeri," Applied and Environmental Microbiology, vol. 44, no. 1, pp. 128-134, 1982.
[44] K. N. Joblin, H. Matsui, G. E. Naylor, and K. Ushida, "Degradation of fresh ryegrass by methanogenic co-cultures of ruminal fungi grown in the presence or absence of Fibrobacter succinogenes," Current Microbiology, vol. 45, no. 1, pp. 46-53, 2002.

[45] K. A. Johnson and D. E. Johnson, "Methane emissions from cattle," Journal of Animal Science, vol. 73, no. 8, pp. 24832492, 1995.

[46] J. B. Holter and A. J. Young, "Methane prediction in dry and lactating Holstein cows," Journal of Dairy Science, vol. 75, no. 8, pp. 2165-2175, 1992.

[47] D. Sauvant and S. Giger-Reverdin, "Empirical modelling meta-analysis of digestive interactions and $\mathrm{CH} 4$ production in ruminants," in Energy and Protein Metabolism and Nutrition, I. Ortigues-Marty, N. Miraux, and W. Brand-Williams, Eds., pp. 561-563, Wageningen Academic, Wageningen, The Netherlands, 2007.

[48] J. A. S. Van Kessel and J. B. Russell, "The effect of pH on ruminal methanogenesis," FEMS Microbiology Ecology, vol. 20, no. 4, pp. 205-210, 1996.

[49] J. G. Ferry, "Methane from acetate," Journal of Bacteriology, vol. 174, no. 17, pp. 5489-5495, 1992.

[50] I. K. Hindrichsen, H. R. Wettstein, A. Machmüller, and M. Kreuzer, "Methane emission, nutrient degradation and nitrogen turnover in dairy cows and their slurry at different milk production scenarios with and without concentrate supplementation," Agriculture, Ecosystems and Environment, vol. 113, no. 1-4, pp. 150-161, 2006.

[51] J. C. Plaizier, D. O. Krause, G. N. Gozho, and B. W. McBride, "Subacute ruminal acidosis in dairy cows: the physiological causes, incidence and consequences," The Veterinary Journal, vol. 176, no. 1, pp. 21-31, 2008.

[52] F. Dohme, A. Machmüller, A. Wasserfallen, and M. Kreuzer, "Ruminal methanogenesis as influenced by individual fatty acids supplemented to complete ruminant diets," Letters in Applied Microbiology, vol. 32, no. 1, pp. 47-51, 2001.

[53] Y. Kong, M. He, T. McAlister, R. Seviour, and R. Forster, "Quantitative fluorescence in situ hybridization of microbial communities in the rumens of cattle fed different diets," Applied and Environmental Microbiology, vol. 76, no. 20, pp. 6933-6938, 2010.

[54] M. Eugène, D. Massé, J. Chiquette, and C. Benchaar, "Metaanalysis on the effects of lipid supplementation on methane production in lactating dairy cows," Canadian Journal of Animal Science, vol. 88, no. 2, pp. 331-334, 2008.

[55] K. A. Beauchemin, M. Kreuzer, F. O’Mara, and T. A. McAllister, "Nutritional management for enteric methane abatement: a review," Australian Journal of Experimental Agriculture, vol. 48, no. 1-2, pp. 21-27, 2008.

[56] A. Machmüller, C. R. Soliva, and M. Kreuzer, "Methanesuppressing effect of myristic acid in sheep as affected by dietary calcium and forage proportion," British Journal of Nutrition, vol. 90, no. 3, pp. 529-540, 2003.

[57] N. E. Odongo, M. M. Or-Rashid, E. Kebreab, J. France, and B. W. McBride, "Effect of supplementing myristic acid in dairy cow rations on ruminal methanogenesis and fatty acid profile in milk," Journal of Dairy Science, vol. 90, no. 4, pp. 18511858, 2007.

[58] C. R. Soliva, L. Meile, A. Cieślak, M. Kreuzer, and A. Machmüller, "Rumen simulation technique study on the interactions of dietary lauric and myristic acid supplementation in suppressing ruminal methanogenesis," British Journal of Nutrition, vol. 92, no. 4, pp. 689-700, 2004. 
[59] S. M. McGinn, K. A. Beauchemin, T. Coates, and D. Colombatto, "Methane emissions from beef cattle: effects of monensin, sunflower oil, enzymes, yeast, and fumaric acid," Journal of Animal Science, vol. 82, no. 11, pp. 3346-3356, 2004.

[60] E. Jordan, D. K. Lovett, F. J. Monahan, J. Callan, B. Flynn, and F. P. O'Mara, "Effect of refined coconut oil or copra meal on methane output and on intake and performance of beef heifers," Journal of Animal Science, vol. 84, no. 1, pp. 162-170, 2006.

[61] K. A. Beauchemin, S. M. McGinn, and H. V. Petit, "Methane abatement strategies for cattle: lipid supplementation of diets," Canadian Journal of Animal Science, vol. 87, no. 3, pp. 431-440, 2007.

[62] G. P. Cosgrove, G. C. Waghorn, C. B. Anderson et al., "The effect of oils fed to sheep on methane production and digestion of ryegrass pasture," Australian Journal of Experimental Agriculture, vol. 48, no. 1-2, pp. 189-192, 2008.

[63] C. Martin, J. Rouel, J. P. Jouany, M. Doreau, and Y. Chilliard, "Methane output and diet digestibility in response to feeding dairy cows crude linseed, extruded linseed, or linseed oil," Journal of Animal Science, vol. 86, no. 10, pp. 2642-2650, 2008.

[64] A. Machmüller and M. Kreuzer, "Methane suppression by coconut oil and associated effects on nutrient and energy balance in sheep," Canadian Journal of Animal Science, vol. 79, no. 1, pp. 65-72, 1999.

[65] A. MacHmüller, D. A. Ossowski, and M. Kreuzer, "Comparative evaluation of the effects of coconut oil, oilseeds and crystalline fat on methane release, digestion and energy balance in lambs," Animal Feed Science and Technology, vol. 85 , no. 1-2, pp. 41-60, 2000.

[66] F. Dohme, A. Machmüller, A. Wasserfallen, and M. Kreuzer, "Comparative efficiency of various fats rich in medium-chain fatty acids to suppress ruminal methanogenesis as measured with RUSITEC," Canadian Journal of Animal Science, vol. 80, no. 3, pp. 473-482, 2000.

[67] E. Jordan, D. Kenny, M. Hawkins, R. Malone, D. K. Lovett, and F. P. O'Mara, "Effect of refined soy oil or whole soybeans on intake, methane output, and performance of young bulls," Journal of Animal Science, vol. 84, no. 9, pp. 2418-2425, 2006.

[68] K. A. Beauchemin, S. M. McGinn, C. Benchaar, and L. Holtshausen, "Crushed sunflower, flax, or canola seeds in lactating dairy cow diets: effects on methane production, rumen fermentation, and milk production," Journal of Dairy Science, vol. 92, no. 5, pp. 2118-2127, 2009.

[69] C. Grainger, R. Williams, T. Clarke, A. D. G. Wright, and R. J. Eckard, "Supplementation with whole cottonseed causes long-term reduction of methane emissions from lactating dairy cows offered a forage and cereal grain diet," Journal of Dairy Science, vol. 93, no. 6, pp. 2612-2619, 2010.

[70] A. Machmüller, C. R. Soliva, and M. Kreuzer, "Effect of coconut oil and defaunation treatment on methanogenesis in sheep," Reproduction Nutrition Development, vol. 43, no. 1, pp. 41-55, 2003.

[71] B. J. Finlay, G. Esteban, K. J. Clarke, A. G. Williams, T. M. Embley, and R. P. Hirt, "Some rumen ciliates have endosymbiotic methanogens," FEMS Microbiology Letters, vol. 117, no. 2, pp. 157-161, 1994.

[72] C. J. Newbold, B. Lassalas, and J. P. Jouany, "The importance of methanogens associated with ciliate protozoa in ruminal methane production in vitro," Letters in Applied Microbiology, vol. 21, no. 4, pp. 230-234, 1995.
[73] R. S. Hegarty, "Reducing rumen methane emissions through elimination of rumen protozoa," Australian Journal of Agricultural Research, vol. 50, no. 8, pp. 1321-1327, 1999.

[74] R. S. Hegarty, S. H. Bird, B. A. Vanselow, and R. Woodgate, "Effects of the absence of protozoa from birth or from weaning on the growth and methane production of lambs," British Journal of Nutrition, vol. 100, no. 6, pp. 1220-1227, 2008.

[75] D. P. Morgavi, J. P. Jouany, and C. Martin, "Changes in methane emission and rumen fermentation parameters induced by refaunation in sheep," Australian Journal of Experimental Agriculture, vol. 48, no. 1-2, pp. 69-72, 2008.

[76] H. Guan, K. M. Wittenberg, K. H. Ominski, and D. O. Krause, "Efficacy of ionophores in cattle diets for mitigation of enteric methane," Journal of Animal Science, vol. 84, no. 7, pp. 1896-1906, 2006.

[77] S. H. Bird, R. S. Hegarty, and R. Woodgate, "Modes of transmission of rumen protozoa between mature sheep," Animal Production Science, vol. 50, no. 6, pp. 414-417, 2010.

[78] A. D. G. Wright, P. Kennedy, C. J. O’Neill et al., "Reducing methane emissions in sheep by immunization against rumen methanogens," Vaccine, vol. 22, no. 29-30, pp. 3976-3985, 2004.

[79] Y. J. Williams, S. Popovski, S. M. Rea et al., "A vaccine against rumen methanogens can alter the composition of archaeal populations," Applied and Environmental Microbiology, vol. 75, no. 7, pp. 1860-1866, 2009.

[80] D. N. Wedlock, G. Pedersen, M. Denis, D. Dey, P. H. Janssen, and B. M. Buddle, "Development of a vaccine to mitigate greenhouse gas emissions in agriculture: vaccination of sheep with methanogen fractions induces antibodies that block methane production in vitro," New Zealand Veterinary Journal, vol. 58, no. 1, pp. 29-36, 2010.

[81] F. D. Sauer, V. Fellner, R. Kinsman et al., "Methane output and lactation response in Holstein cattle with monensin or unsaturated fat added to the diet," Journal of Animal Science, vol. 76, no. 3, pp. 906-914, 1998.

[82] W. G. Bergen and D. B. Bates, "Ionophores: their effect on production efficiency and mode of action," Journal of Animal Science, vol. 58, no. 6, pp. 1465-1483, 1984.

[83] J. B. Russell and H. J. Strobel, "Effect of ionophores on ruminal fermentation," Applied and Environmental Microbiology, vol. 55, no. 1, pp. 1-6, 1989.

[84] M. Chen and M. J. Wolin, "Effect of monensin and lasalocidsodium on the growth of methanogenic and rumen saccharolytic bacteria," Applied and Environmental Microbiology, vol. 38, no. 1, pp. 72-77, 1979.

[85] C. J. Van Nevel and D. I. Demeyer, "Effect of monensin on rumen metabolism in vitro," Applied and Environmental Microbiology, vol. 34, no. 3, pp. 251-257, 1977.

[86] N. E. Odongo, R. Bagg, G. Vessie et al., "Long-term effects of feeding monensin on methane production in lactating dairy cows," Journal of Dairy Science, vol. 90, no. 4, pp. 1781-1788, 2007.

[87] S. E. Hook, K. S. Northwood, A. D. G. Wright, and B. W. McBride, "Long-term monensin supplementation does not significantly affect the quantity or diversity of methanogens in the rumen of the lactating dairy cow," Applied and Environmental Microbiology, vol. 75, no. 2, pp. 374-380, 2009.

[88] M. H. Tavendale, L. P. Meagher, D. Pacheco, N. Walker, G. T. Attwood, and S. Sivakumaran, "Methane production from in vitro rumen incubations with Lotus pedunculatus and Medicago sativa, and effects of extractable condensed 
tannin fractions on methanogenesis," Animal Feed Science and Technology, vol. 123-124, pp. 403-419, 2005.

[89] R. Puchala, B. R. Min, A. L. Goetsch, and T. Sahlu, "The effect of a condensed tannin-containing forage on methane emission by goats," Journal of Animal Science, vol. 83, no. 1, pp. 182-186, 2005.

[90] J. E. Carulla, M. Kreuzer, A. Machmüller, and H. D. Hess, "Supplementation of Acacia mearnsii tannins decreases methanogenesis and urinary nitrogen in forage-fed sheep," Australian Journal of Agricultural Research, vol. 56, no. 9, pp. 961-970, 2005.

[91] T. T. Tiemann, C. E. Lascano, H. R. Wettstein, A. C. Mayer, M. Kreuzer, and H. D. Hess, "Effect of the tropical tanninrich shrub legumes Calliandra calothyrsus and Flemingia macrophylla on methane emission and nitrogen and energy balance in growing lambs," Animal, vol. 2, no. 5, pp. 790-799, 2008.

[92] K. A. Beauchemin, S. M. McGinn, T. F. Martinez, and T. A. McAllister, "Use of condensed tannin extract from quebracho trees to reduce methane emissions from cattle," Journal of Animal Science, vol. 85, no. 8, pp. 1990-1996, 2007.

[93] S. G. de Oliveira, T. T. Berchielli, M. D. S. Pedreira, O. Primavesi, R. Frighetto, and M. A. Lima, "Effect of tannin levels in sorghum silage and concentrate supplementation on apparent digestibility and methane emission in beef cattle," Animal Feed Science and Technology, vol. 135, no. 3-4, pp. 236-248, 2007.

[94] Y. Q. Guo, J. X. Liu, Y. Lu, W. Y. Zhu, S. E. Denman, and C. S. McSweeney, "Effect of tea saponin on methanogenesis, microbial community structure and expression of mcrA gene, in cultures of rumen micro-organisms," Letters in Applied Microbiology, vol. 47, no. 5, pp. 421-426, 2008.

[95] L. Holtshausen, A. V. Chaves, K. A. Beauchemin et al., "Feeding saponin-containing Yucca schidigera and Quillaja saponaria to decrease enteric methane production in dairy cows," Journal of Dairy Science, vol. 92, no. 6, pp. 2809-2821, 2009.

[96] S. Burt, "Essential oils: their antibacterial properties and potential applications in foods-a review," International Journal of Food Microbiology, vol. 94, no. 3, pp. 223-253, 2004.

[97] S. Calsamiglia, M. Busquet, P. W. Cardozo, L. Castillejos, and A. Ferret, "Invited review: essential oils as modifiers of rumen microbial fermentation," Journal of Dairy Science, vol. 90, no. 6, pp. 2580-2595, 2007.

[98] K. A. Beauchemin and S. M. McGinn, "Methane emissions from beef cattle: effects of fumaric acid, essential oil, and canola oil," Journal of Animal Science, vol. 84, no. 6, pp. 14891496, 2006.

[99] T. A. Wood, R. J. Wallace, A. Rowe et al., "Encapsulated fumaric acid as a feed ingredient to decrease ruminal methane emissions," Animal Feed Science and Technology, vol. 152, no. 1-2, pp. 62-71, 2009.

[100] G. Molano, T. W. Knight, and H. Clark, "Fumaric acid supplements have no effect on methane emissions per unit of feed intake in wether lambs," Australian Journal of Experimental Agriculture, vol. 48, no. 1-2, pp. 165-168, 2008.

[101] P. A. Foley, D. A. Kenny, J. J. Callan, T. M. Boland, and F. P. O'Mara, "Effect of DL-malic acid supplementation on feed intake, methane emission, and rumen fermentation in beef cattle," Journal of Animal Science, vol. 87, no. 3, pp. 10481057, 2009. 

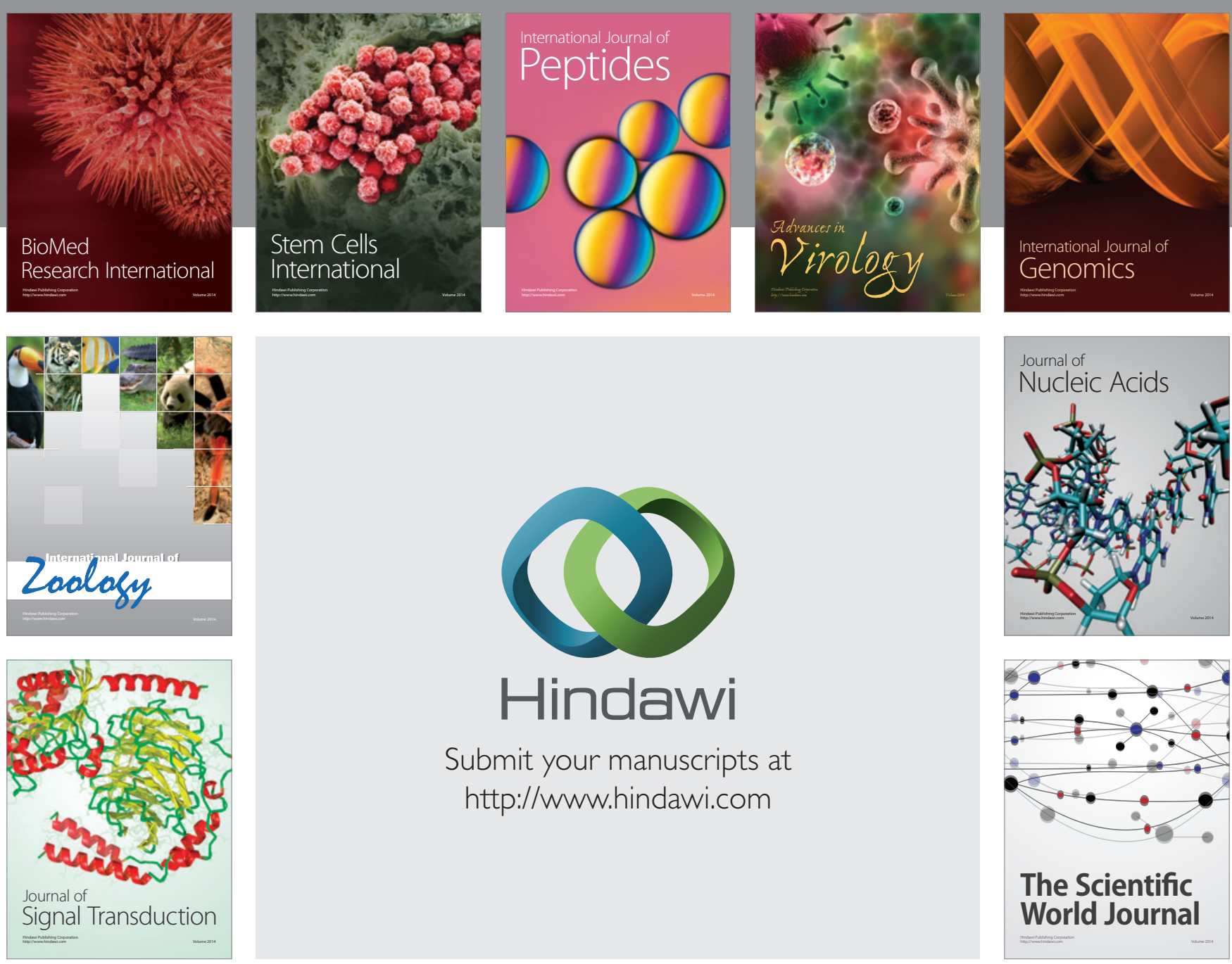

Submit your manuscripts at

http://www.hindawi.com
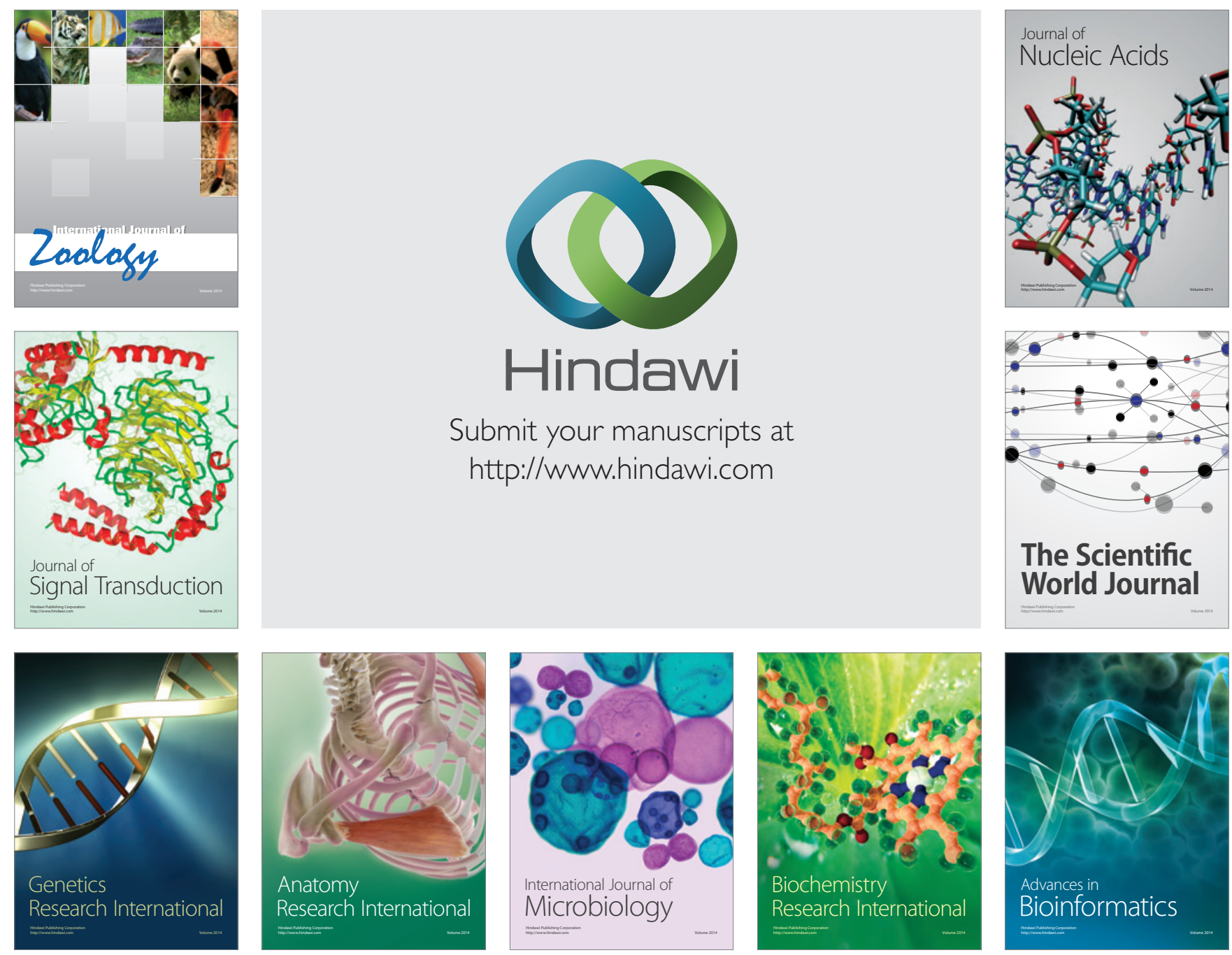

The Scientific World Journal
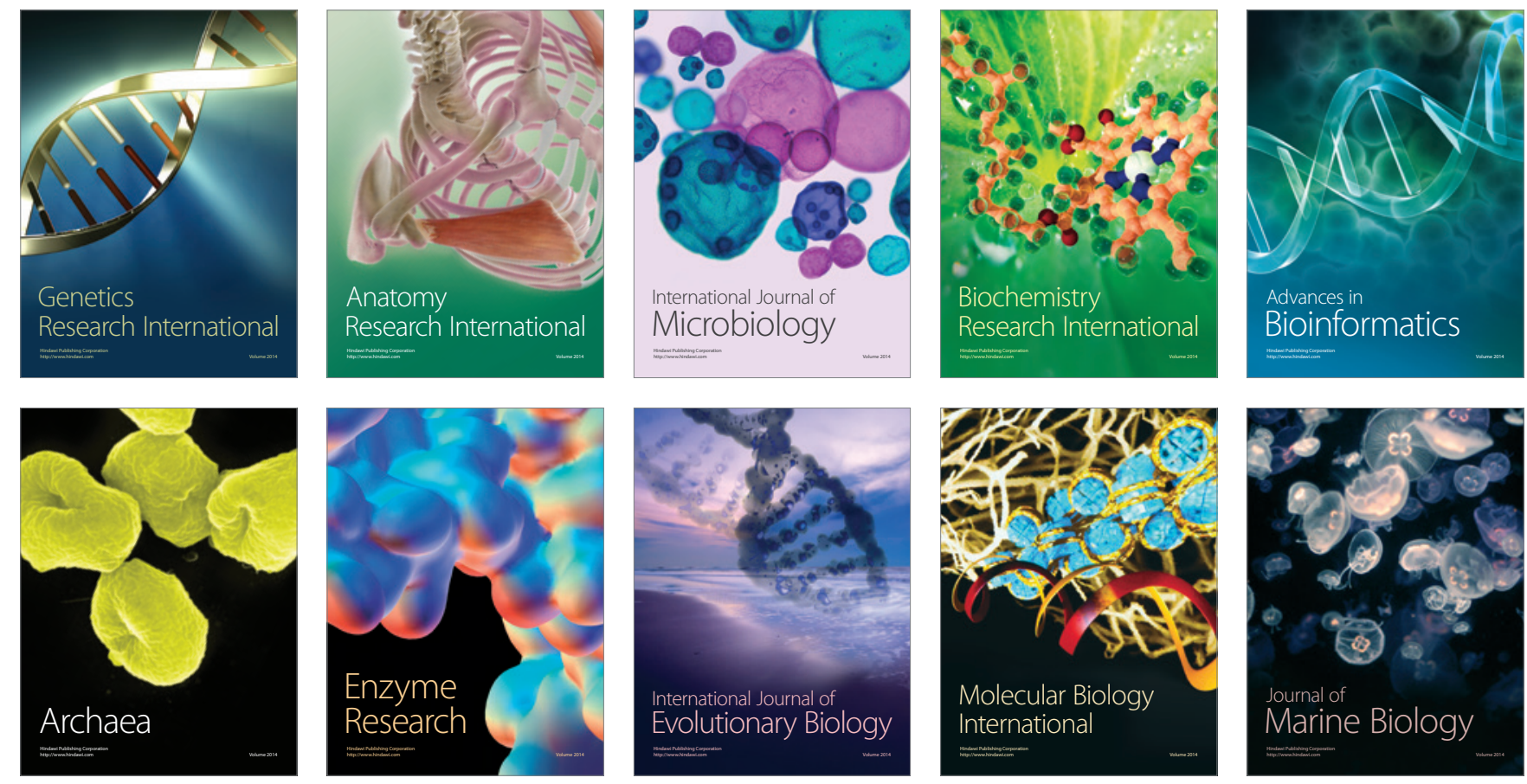